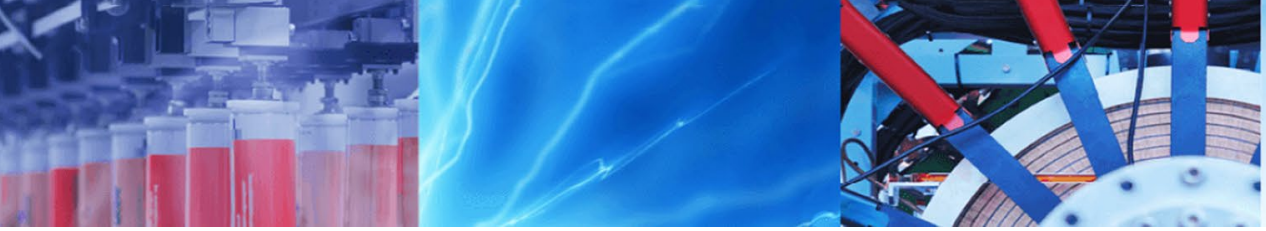

Research Article

\title{
A one-pot synthesis of colloidal Ag-Au nanoparticles with controlled composition
}

\author{
Gvidona P. Shevchenko ${ }^{1}$. Victor A. Zhuravkov ${ }^{1}$ (D) Galina V. Shishko ${ }^{1}$
}

(c) Springer Nature Switzerland AG 2019

\begin{abstract}
We report a one-pot synthesis method for a production of a stable Ag-Au bimetal colloidal solutions (Ag-Au hydrosols) by simply mixing disodium salt of ethylenediaminetetraacetic acid $\left(\mathrm{Na}_{2} \mathrm{EDTA}\right)$ with $\mathrm{AgNO}_{3}$ and $\mathrm{HAuCl}_{4}$ in aqueous alkaline medium at $80^{\circ} \mathrm{C}$. We found that $\mathrm{Na}_{2} \mathrm{EDTA}$ act not only as a reductant of metal ions and a potent stabilizer of metal nanoparticle size, but also as an effective agent for controlling the composition of the formed nanoparticles, owing to the high complexing affinity of $\mathrm{Na}_{2}$ EDTA to silver ions. It was found that by controlling $\mathrm{Na}_{2}$ EDTA concentration in the reaction mixture it is possible to control not only size and size distribution of a synthesized colloidal bimetallic $\mathrm{Ag}-\mathrm{Au}$ nanoparticles, but bimetallic $\mathrm{Ag}-\mathrm{Au}$ nanoparticles composition (Ag/Au ratio) as well.
\end{abstract}

\section{Graphic abstract}

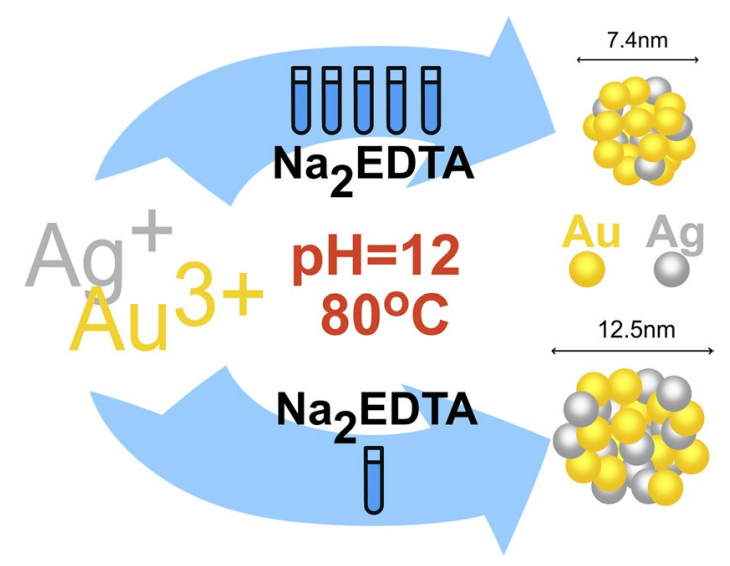

Keywords Bimetal Ag-Au synthesis $\cdot$ Nanoparticles $\cdot \mathrm{Ag} \cdot \mathrm{Au} \cdot \mathrm{Hydrosols} \cdot \mathrm{Na}_{2}$ EDTA

\section{Introduction}

Currently, systems consisting of precious metal-based nanoparticles with intensive absorption bands in the visible optical region are widely employed in a vast variety of practical applications. Gold and silver nanoparticles exhibiting surface plasmon resonance (SPR) are of practical interest due to the possibility to tune the spectral position and SPR amplitude by changing composition, size, shape, structure and dielectric surrounding of the nanoparticles

Victor A.Zhuravkov, zhuravkovv@bsu.by; zhuravkov@gmail.com; Gvidona P. Shevchenko, shevchenko@bsu.by; gvidonashevchenko@gmail.com; Galina V. Shishko, galashishko@gmail.com | ${ }^{1}$ Research Institute for Physical Chemical Problems, Belarusian State University, 14 Leningradskaya DNR Street, 220006 Minsk, Belarus. 
[1-5]. From the practical standpoint, aside from the morphology and size of such nanoparticle their composition is also a crucial parameter. Composition control opens an additional way for controlling optoelectronic properties and also may enhance the practically important nanoparticle characteristics. For example, it was demonstrated in Ref. [6] that the composition of bimetallic nanoparticles plays an essential role in nonenzymatic detection.

Methods for the preparation of bimetallic Ag-Au nanoparticles using various reducing agents are the subject of a numerous papers [7-12]. For example, in Ref. [13] authors used trimethylamine borane (a reducing agent with relatively low activity) for the preparation of bimetallic nanoparticles with controlled size distribution by exploiting the different reduction rates of silver and gold. In Ref. [14] authors reported the preparation of Ag-Au nanoparticles with controlled composition by the reduction of precursors with oleylamine in the organic medium at different temperatures. In most cases composition control is achieved by varying the relative molar concentration of reactants [15-18] and at the same time a linear relationship between this reaction parameter and the $\mathrm{Ag} / \mathrm{Au}$ ratio in the final bimetallic nanoparticles is noted.

Regardless of the current progress made in developing of the synthetic procedures, the choice of the reported approaches to the preparation of bimetallic nanoparticles still remains somewhat limited and involved protocols are usually relatively sophisticated. Also, in Ref. [19] authors suggest that the synthetic protocols for high-quality bimetallic nanoparticles with controllable size, morphology, composition and structure have not been sufficiently well-developed thus far.

In this paper we report a simple and single-step approach to the preparation of bimetallic Ag-Au colloids that employs $\mathrm{Na}_{2}$ EDTA, which simultaneously acts as a reductant and an effective agent for regulating the composition of obtained nanoparticles. While synthetic protocols for the preparation of nanoparticles consisting of individual gold or silver using $\mathrm{Na}_{2}$ EDTA (or EDTA) are relatively well-known [20-25], $\mathrm{Na}_{2}$ EDTA-based syntheses of bimetallic $\mathrm{Ag}$-Au nanoparticles have not yet been reported in the literature.

\section{Experimental part}

Colloidal Ag-Au nanoparticles were synthesized using $0.008 \mathrm{M} \mathrm{Na}_{2}$ EDTA, $0.075 \mathrm{M} \mathrm{NaOH}, 0.01 \mathrm{M} \mathrm{AgNO}_{3}$ and $0.023 \mathrm{M} \mathrm{HAuCl}_{4}$ solutions. In the major set of experiments (except specifically noted cases) the molar ratios of $(\mathrm{Ag}+\mathrm{Au}) / \mathrm{Na}_{2} \mathrm{EDTA}$ and $\mathrm{Ag} / \mathrm{Au}$ were set equal 1. Total metal concentration $(\mathrm{Ag}+\mathrm{Au})$ in all experiment was $5 \times 10^{-4} \mathrm{M}$.

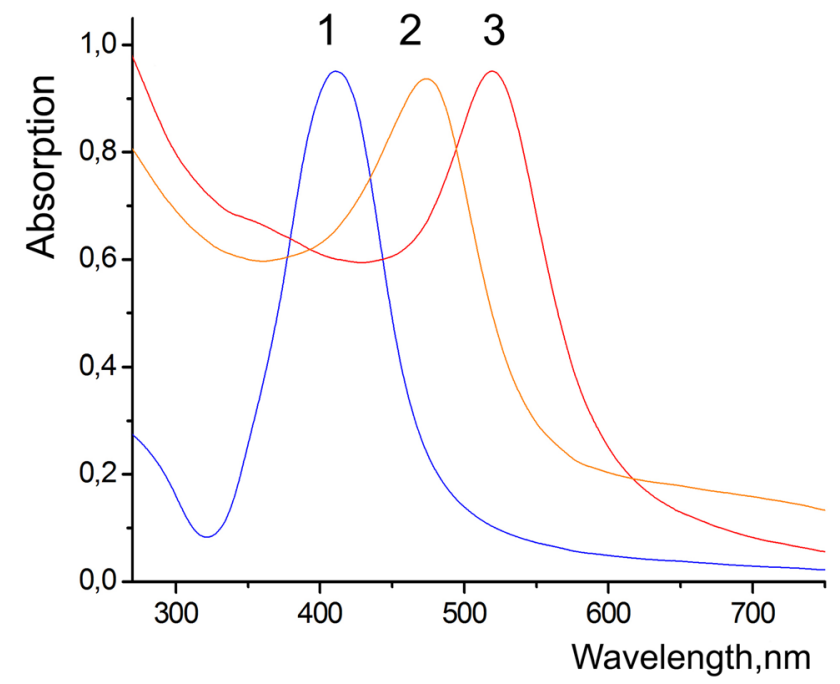

Fig. 1 Normalised absorption spectra of colloidal solutions of silver (1), gold (3) and bimetallic (2) nanoparticles prepared at the molar ratios $\mathrm{Me} / \mathrm{Na}_{2} \mathrm{EDTA}=1, \mathrm{Ag} / \mathrm{Au}=1$ at $80^{\circ} \mathrm{C}$. Reaction time is $20 \mathrm{~min}$

The synthesis was carried according to the following protocol. Under the intensive stirring, in a $100 \mathrm{ml}$ reaction flask $39.1 \mathrm{ml}$ of distilled water was mixed with $6 \mathrm{ml}$ of $\mathrm{NaOH}$ solution and with $3.1 \mathrm{ml}$ of $\mathrm{Na}_{2}$ EDTA solution; then this solution with $\mathrm{pH} 12.0$ alkalinity was heated to $80^{\circ} \mathrm{C}$. The sequence of the further addition of reagents is of principal importance, since it is known that when both silver nitrate and hydrogen tetrachloroaurate are simultaneously present in the solution, insoluble silver chloride may form [8]. In order to avoid this adverse side reaction, $1.25 \mathrm{ml}$ of $\mathrm{AgNO}_{3}$ solution was added first to the hot $\mathrm{pH} 12.0$ alkaline $\mathrm{Na}_{2}$ EDTA basic solution to produce a clear solution of the strong silver complex with EDTA. Almost immediately after that, $0.55 \mathrm{ml}$ of $\mathrm{HAuCl}_{4}$ solution was added under vigorous stirring and after $5-10$ s the reaction mixture changed colour, so that the final volume of the reaction mixture was $50 \mathrm{ml}$. For comparison, colloidal solutions of individual silver and gold nanoparticles were prepared under identical conditions.

Samples of colloidal nanoparticles were characterized using optical spectroscopy, transmission electron microscopy (TEM). Optical absorption spectra in $200-800 \mathrm{~nm}$ wavelength range were acquired using Cary 500 doublebeam spectrophotometer. The composition of nanoparticles was determined by inductively coupled plasma optical emission spectrometry using Prodigy Plus analyser.

\section{Results and discussion}

Figure 1 shows optical absorption spectra of bimetallic (line 2) and individual (lines 1 and 3) metal nanoparticles. The appearance of only one absorption band in the 
spectrum of the colloidal solution of bimetallic nanoparticles $\left(\lambda_{\max }=472 \mathrm{~nm}\right)$ positioned practically in the middle relative to the absorption band of silver $\left(\lambda_{\max }=418 \mathrm{~nm}\right)$ and gold $\left(\lambda_{\max }=520 \mathrm{~nm}\right)$ nanoparticles, indicates of the formation bimetallic alloy.

The presence of only one absorption band (Fig. 1, curve c) in the spectrum of the bimetallic sol $\left(\lambda_{\max }=472 \mathrm{~nm}\right)$, located almost in the middle relative to the absorption bands of silver $\left(\lambda_{\max }=418 \mathrm{~nm}\right)$ and gold $\left(\lambda_{\max }=520 \mathrm{~nm}\right)$, indicates that alloy particles of two metals are formed.

Figure 2 shows TEM-images and particles size distribution of the obtained colloidal nanoparticles. As one can see, Ag-Au bimetallic nanoparticles have spherical shape, narrow size distribution and the mean size of approximately $10 \mathrm{~nm}$, while the nanoparticles of individual metals prepared under the same conditions are larger and less uniform in size.

In further work, the influence of the concentration of $\mathrm{Na}_{2} \mathrm{EDTA}$ on the formation of bimetallic sols was studied in more details. Figure 3 shows the $\lambda_{\max }$ of the colloidal solutions of the obtained $\mathrm{Ag}$-Au nanoparticles as a function of the $\mathrm{Ag} / \mathrm{Au}$ molar ratio in the starting reaction mixture at different $\mathrm{Na}_{2}$ EDTA concentrations. Similar studies with various reducing agents (but not $\mathrm{Na}_{2}$ EDTA) were conducted earlier [15-18], where a linear dependence was observed. However, our results demonstrate that the investigated dependence is more complex and is altered considerably by the changes in the $\mathrm{Na}_{2}$ EDTA concentration in the reaction mixture (Fig. 3a-c).

Figure 4 shows the $\lambda_{\max }$ position in the optical absorption spectra of the colloidal solution of $\mathrm{Ag}$-Au nanoparticles as a function of the reaction time at different $\mathrm{Na}_{2} \mathrm{EDTA}$ concentrations. When there is "insufficient" $\mathrm{Na}_{2} \mathrm{EDTA}$, i.e. molar concentration of $\mathrm{Na}_{2}$ EDTA is lower than the sum of molar concentrations of starting metals (Fig. 4, line 3), the reaction is inhibited and starts approximately after $5 \mathrm{~min}$ after the injection of all reagents. Then a slight redshift of the absorption spectrum is observed and $\lambda_{\max }$ changes

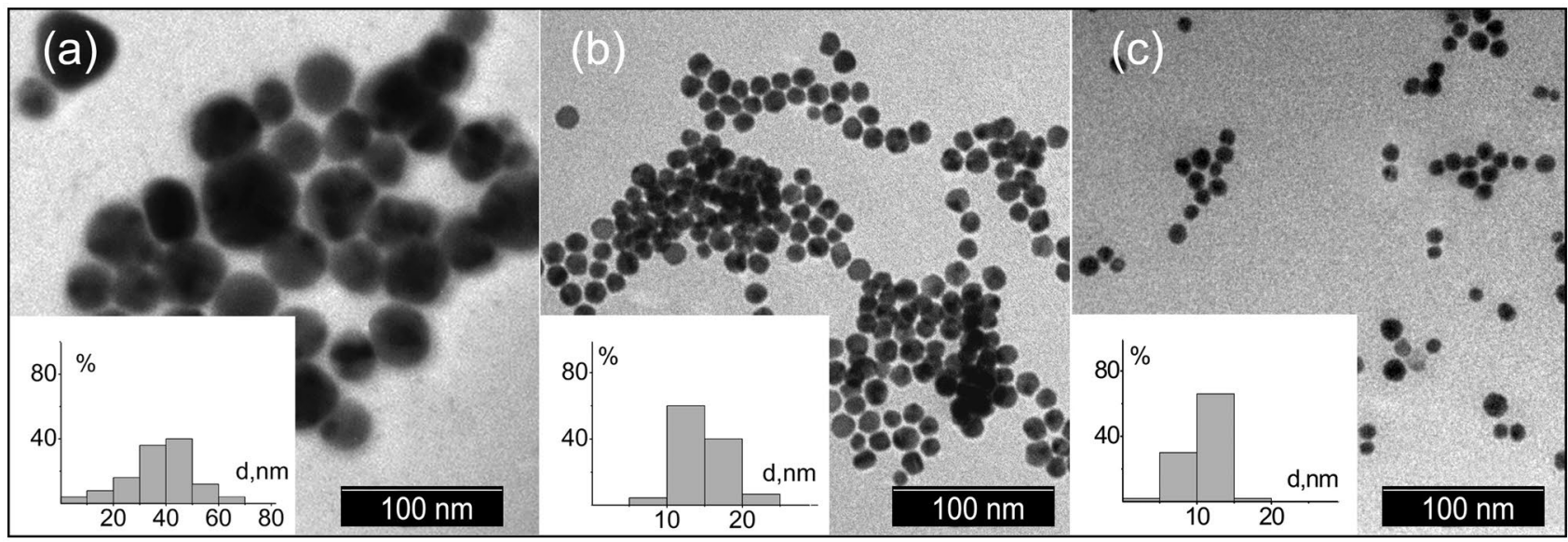

Fig. 2 TEM-images and particle size distribution of colloidal metallic nanoparticles prepared in identical conditions: $\mathbf{a}-\mathrm{Ag}, \mathbf{b}-\mathrm{Au}, \mathbf{c}-\mathrm{Ag}-$ Au bimetal

(a)

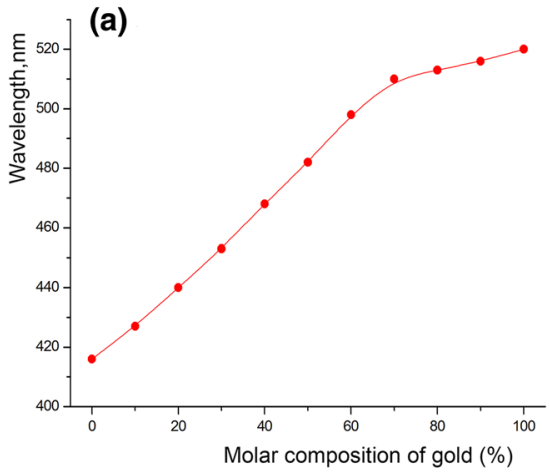

(b)

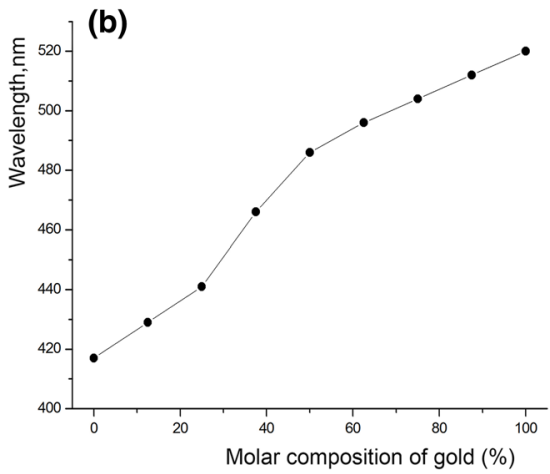

(c)

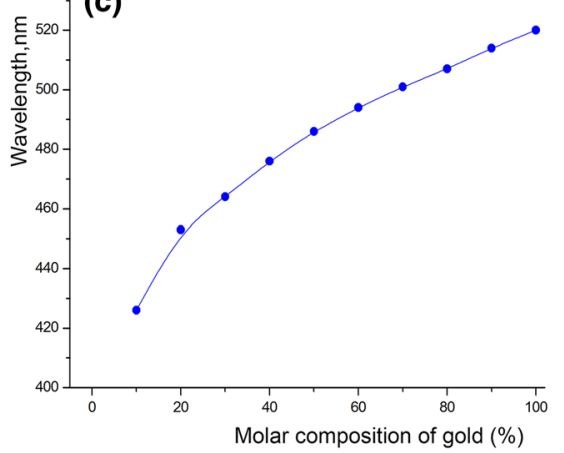

Fig. 3 The influence of $\mathrm{Ag} / \mathrm{Au}$ molar ratio in the starting reaction mixture on the $\lambda_{\max }$ position in the optical absorption spectra at different $\mathrm{Na}_{2}$ EDTA concentrations: $\mathbf{a}-1.25 \times 10^{-4} \mathrm{M} ; \mathbf{b}-5 \times 10^{-4} \mathrm{M} ; \mathbf{c}-2 \times 10^{-3} \mathrm{M}$; reaction time is $20 \mathrm{~min}$ 


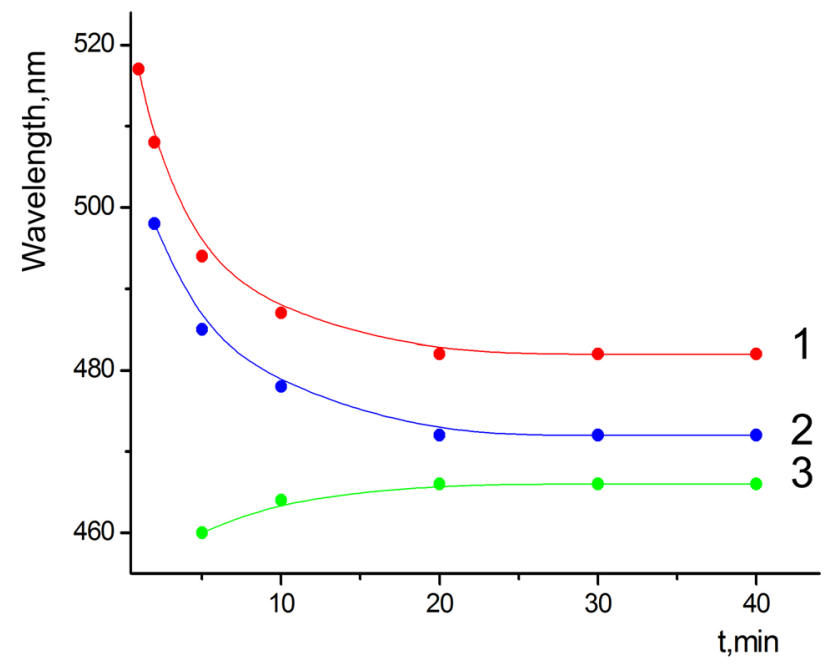

Fig. 4 Variation of $\lambda_{\max }$ in the absorption spectra of $\mathrm{Ag}-\mathrm{Au}$ colloidal solutions in time at different concentration of $\mathrm{Na}_{2} \mathrm{EDTA}$ : $1-2 \times 10^{-3} \mathrm{M} ; 2-5 \times 10^{-4} \mathrm{M} ; 3-1.25 \times 10^{-4} \mathrm{M} ; \mathrm{Ag} / \mathrm{Au}$ molar ratio $=1,[\mathrm{Ag}+\mathrm{Au}]=5 \times 10^{-4} \mathrm{M}$

from 460 to $467 \mathrm{~nm}$ (until $20 \mathrm{~min}$ ); after that the position of $\lambda_{\max }$ remains unchanged until the end of the reaction ( $40 \mathrm{~min}$ ). Moreover, judging by the value of $\lambda_{\max }=460 \mathrm{~nm}$, bimetal nanoparticles with a predominance of silver are formed from the very beginning of the reaction.

At the high excess of $\mathrm{Na}_{2} \mathrm{EDTA}$, i.e. when the molar concentration of $\mathrm{Na}_{2}$ EDTA is 4 times higher than the sum of molar concentrations of starting metals (Fig. 4, line 1), a completely different behaviour is observed. As indicated by the visually noticeable colour change, the reaction starts several seconds after the injection of all reagents.

Judging by value of $\lambda_{\max }=517 \mathrm{~nm}$, from the very beginning of the reaction, almost pure gold nanoparticles are formed. But over time scene changes rapidly, position of $\lambda_{\max }$ shifts into the short wavelength region and stabilizes approximately after $20 \mathrm{~min}$. Further increase of the reaction time (>20 min) does not result in significant changes of the $\lambda_{\max }$ at all investigated $\mathrm{Na}_{2}$ EDTA concentrations (Fig. 4, lines 1-3).

TEM-studies (Fig. 5) of the prepared colloids show that $\mathrm{Na}_{2}$ EDTA concentration also considerably alters the average size and size distribution of the Ag-Au nanoparticles.

At lower $\mathrm{Na}_{2}$ EDTA concentration the average size of Ag-Au nanoparticles increases and the size distribution becomes broader. It is worth pointing out that the stability of the prepared colloidal solutions also depends on the $\mathrm{Na}_{2}$ EDTA concentration: at $\left[\mathrm{Na}_{2}\right.$ EDTA $] \geq 5 \times 10^{-4} \mathrm{M}$ solutions remain stable for more than 1 year, while al lower concentration $\left(\left[\mathrm{Na}_{2} \mathrm{EDTA}\right]=1.25 \times 10^{-4} \mathrm{M}\right)$ solution are stable only for several weeks.

Considerable difference of $\lambda_{\max }$ in the absorption spectra of the colloidal solutions prepared using different $\mathrm{Na}_{2}$ EDTA concentrations suggests that nanoparticles in these solutions have different composition. To test this assumption a series of analyses were conducted using inductively coupled plasma optical emission spectrometry. Measurement results are provided in the following Table 1 along with the data obtained using optical spectroscopy and TEM.

As one can see from the table, at the same molar ratio of the starting reagents $(\mathrm{Ag} / \mathrm{Au}=1)$ as the $\mathrm{Na}_{2}$ EDTA concentration decreases, the nanoparticles become enriched in silver and at the same time their size increases. It is interesting to note that such a trend, i.e. the simultaneous increase in the silver content and nanoparticle size is similar to the one reported in Ref. [13], although the synthetic protocol for bimetallic nanoparticles employed in that paper is completely different (reduction with oleylamine in organic medium).

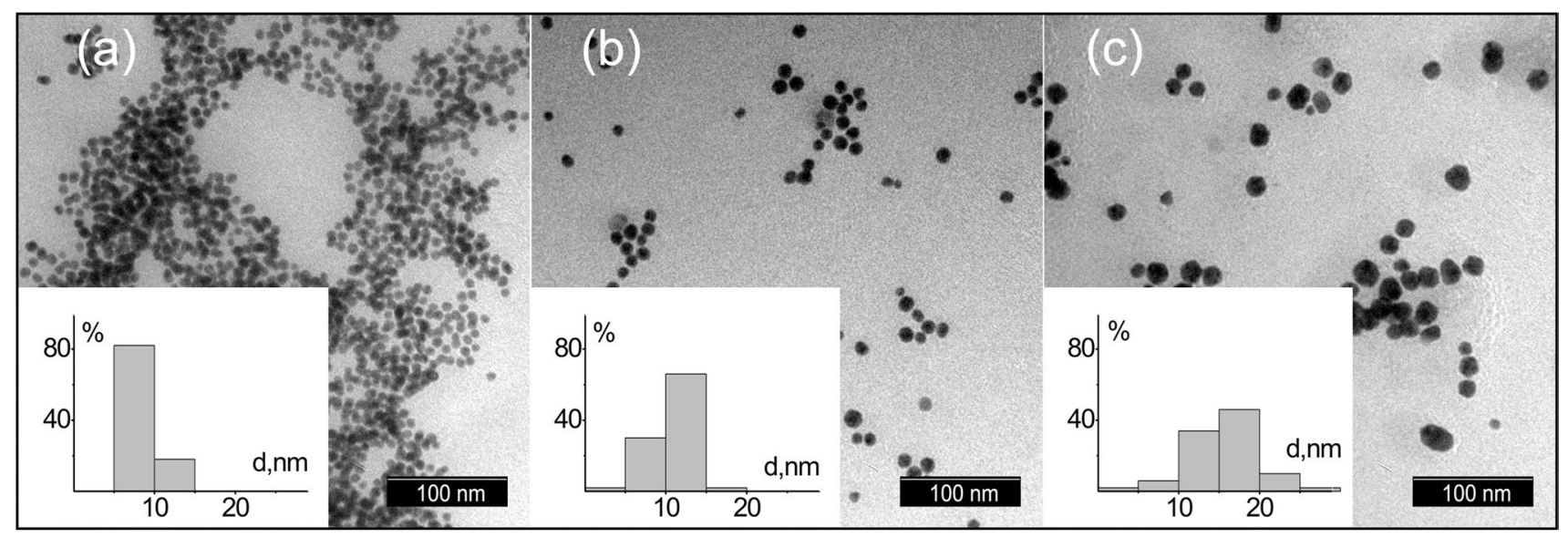

Fig. 5 TEM-images of Ag-Au nanoparticles prepared at different $\mathrm{Na}_{2}$ EDTA concentrations in the reaction mixture $(\mathrm{Ag} / \mathrm{Au}=1$, time $-20 \mathrm{~min})$ : a- $2 \times 10^{-3} \mathrm{M} ; \mathbf{b}-5 \times 10^{-4} \mathrm{M} ; \mathbf{c}-1.25 \times 10^{-4} \mathrm{M}$ 
Table 1 Characteristics of the colloidal solutions of $\mathrm{Ag}-\mathrm{Au}$ bimetallic nanoparticles as a function of $\mathrm{Na}_{2}$ EDTA concentration (Ag/Au molar ratio $=1$, reaction time$20 \mathrm{~min})$

\begin{tabular}{llll}
\hline $\begin{array}{l}\mathrm{Na}_{2} \text { EDTA concentration in the } \\
\text { reaction mixture (M) }\end{array}$ & $\begin{array}{l}\text { Position of } \lambda_{\max } \\
(\mathrm{nm})\end{array}$ & $\begin{array}{l}\mathrm{Ag} / \text { Au molar ratio in } \\
\text { the bimetal (\%) }\end{array}$ & $\begin{array}{l}\text { Average diameter of the } \\
\text { bimetallic nanoparticles } \\
(\mathrm{nm})\end{array}$ \\
\hline $2 \times 10^{-3}$ & 483 & $25 / 75$ & 7.4 \\
$5 \times 10^{-4}$ & 472 & $40 / 60$ & 10.4 \\
$1.25 \times 10^{-4}$ & 466 & $45 / 55$ & 12.5 \\
\hline
\end{tabular}

\section{Discussion}

Obtained experimental results demonstrate that the composition of bimetallic nanoparticles, their size and size distribution is determined by the concentration of $\mathrm{Na}_{2} \mathrm{EDTA}$. Theoretical modelling [26] shows that the $\lambda_{\max }$ in the absorption spectra of the $\mathrm{Ag}-\mathrm{Au}$ spherical nanoparticles is almost linearly dependent on their composition, i.e. the molar ratio of metals in the particle. It should be emphasized that in the majority of works reporting the synthesis of Ag-Au nanoparticles using a range of different reducing agents [15-18] a good correlation with theoretical calculations was observed. However, our results differ noticiably from the data mentioned above.

Such a discrepancy from the existing data may be explained in the following manner. In our case $\mathrm{Na}_{2}$ EDTA plays several different roles. Firstly, it is a reducing agent ensuring the formation of metallic nanoparticles. Secondly, it acts as a stabilizing agent providing small size of the prepared particles (bimetallic nanoparticles are known to reach $100 \mathrm{~nm}$ and more in size in the absence of stabilizing agents [6]). Thirdly, $\mathrm{Na}_{2}$ EDTA forms complex compounds with metal ions, and especially strong ones with $\mathrm{Ag}^{+}\left(\mathrm{pK}_{1}=7.31, \mathrm{pK}_{2}=11.31\right.$ [27]). In addition to that $\mathrm{Na}_{2}$ EDTA is known to act as a reducing agent for $\mathrm{Au}^{3+}$ ions in the broad range of $\mathrm{Au} / \mathrm{Na}_{2} \mathrm{EDTA}$ ratios from $1 / 0.3$ to $1 / 100[18,28]$. As we have demonstrated earlier [29], silver colloids are formed at $\mathrm{Ag} / \mathrm{Na}_{2} \mathrm{EDTA}=(1 / 1 \div 2 / 1)$, that is, when the concentration of $\mathrm{Na}_{2}$ EDTA is less than the concentration of $\mathrm{Ag}^{+}$. While at higher $\mathrm{Na}_{2}$ EDTA concentrations $\left(\mathrm{Ag} / \mathrm{Na}_{2} \mathrm{EDTA}<1\right)$, that is, when the concentration of $\mathrm{Na}_{2} \mathrm{EDTA}$ is higher than the concentration of $\mathrm{Ag}^{+}$, no reaction occurs. Taking into account all the presented above considerations, the observed peculiar effect of the $\mathrm{Na}_{2} \mathrm{EDTA}$ concentration on the $\lambda_{\max }$ dependence of the metals $\mathrm{Ag} / \mathrm{Au}$ molar ratio is related to $\mathrm{Na}_{2}$ EDTA silver chelating ability. As a result, silver complex compounds of different composition are formed, and a change in the composition of these complexes occurs during the reaction. Thereby silver complex compounds of different composition are forming and transforming over the course of the reaction.

At low concentrations $\left(1.25 \times 10^{-4} \mathrm{M}\right.$, ratio $\mathrm{Ag} / \mathrm{Na}_{2} \mathrm{E}-$ DTA $=2 / 1$ ) complexing ability of $\mathrm{Na}_{2}$ EDTA is not too significant and thus the relationship between $\lambda_{\max }$ position of Ag-Au colloids and the Ag/Au molar ratio is almost linear, except for the low silver concentration region (Fig. 3a). On the contrary, at significant $\mathrm{Na}_{2}$ EDTA concentrations $\left(2 \times 10^{-3} \mathrm{M}\right.$, ratio $\left.\mathrm{Ag} / \mathrm{Na}_{2} \mathrm{EDTA}=1 / 8\right)$ complexing ability of $\mathrm{Na}_{2}$ EDTA is significant and therefore $\mathrm{Na}_{2}$ EDTA almost entirely hinder silver nanoparticles formation and as a result at first primarily gold nanoparticles are formed (Fig. 4, initial area of line 1). In this case, the absence of the zero point on the line (Fig. $3 \mathrm{C}$ ) is very significant and indicates that at high $\mathrm{Na}_{2}$ EDTA concentrations $\left(2 \times 10^{-3} \mathrm{M}\right)$, in the absence of $\mathrm{Au}$, the synthesis reaction does not occur. In the case of high $\mathrm{Na}_{2}$ EDTA concentrations $\left(2 \times 10^{-3} \mathrm{M}\right)$ we assume, that gold nanoparticles are formed on early stages of the reaction and then serve as a catalyst for the reduction of silver ions and thus as a result final bimetallic nanoparticles are "enriched" with gold (see Table 1). To test this assumption, we conducted the following experiment. We added $2 \%$ molar mass (to the molar mass of silver) of pre-synthesized gold nanoparticles to the reaction medium with high concentration of $\mathrm{Na}_{2}$ EDTA $\left(2 \times 10^{-3} \mathrm{M}\right)$ and obtained a silver colloid with a pronounced plasmon peak at $\lambda_{\max }=418 \mathrm{~nm}$, which, in our opinion, indicates the formation of silver nanoparticles. As we established earlier [29], under such conditions (in the presence of high concentration of $\mathrm{Na}_{2} \mathrm{EDTA}$ ) without gold nanoparticles the synthesis reaction of silver nanoparticles does not occur.

\section{Conclusions}

This paper for the first time demonstrates a method of one-pot preparation of stable colloids of bimetallic $\mathrm{Ag}-\mathrm{Au}$ nanoparticles using $\mathrm{Na}_{2}$ EDTA without any polymeric stabilizing agents. $\mathrm{Na}_{2}$ EDTA was found to act not only as a reductant of metal ions but also as an effective agent for controlling the composition of the formed nanoparticles, which may be explained by the high complexing ability of $\mathrm{Na}_{2}$ EDTA to silver ions. It was found that by controlling $\mathrm{Na}_{2}$ EDTA concentration in the reaction mixture when other reaction parameters are fixed (most importantly the concentration of $\mathrm{Ag}$ and $\mathrm{Au}$ salts) it is possible to control composition (Ag/Au ratio), size and size distribution of a synthesized colloidal bimetallic Ag-Au nanoparticles. 
Acknowledgements This work has been supported by the Belarusian State Program of Scientific Research "Photonics, Opto- and Microelectronics" (Task No. 1.2.03).

\section{Compliance with ethical standards}

Conflict of interest The authors declare that they have no conflict of interests.

\section{References}

1. Rosi NL, Mirkin CA (2005) Nanostructures in biodiagnostics. Chem Rev 105:1547-1562. https://doi.org/10.1021/cr030067f

2. de la Fuente JM, Penadés S (2006) Glyconanoparticles: types, synthesis and applications in glycoscience, biomedicine and material science. Biochim Biophys Acta Gen Subj 1760:636-651. https://doi.org/10.1016/j.bbagen.2005.12.001

3. Liu YC, Yang SJ (2007) Improved surface-enhanced Raman scattering based on $\mathrm{Ag}-\mathrm{Au}$ bimetals prepared by galvanic replacement reactions. Electrochim Acta 52:1925-1931. https://doi. org/10.1016/j.electacta.2006.07.057

4. Chen Y, Wu H, Li Z, Wang P, Yang L, Fang Y (2012) The study of surface plasmon in Au/Ag core/shell compound nanoparticles. Plasmonics 7:509-513. https://doi.org/10.1007/s1146 8-012-9336-6

5. Major KJ, De C, Obare SO (2009) Recent advances in the synthesis of plasmonic bimetallic nanoparticles. Plasmonics 4:61-78. https://doi.org/10.1007/s11468-008-9077-8

6. Li W, Kuai L, Qin Q, Geng B (2013) Ag-Au bimetallic nanostructures: co-reduction synthesis and their component-dependent performance for enzyme-free $\mathrm{H}_{2} \mathrm{O}_{2}$ sensing. J Mater Chem $\mathrm{A}$ 1:7111-7117. https://doi.org/10.1039/c3ta00106g

7. Deng L, Hu W, Deng H, Xiao S, Tang J (2011) Au-Ag bimetallic nanoparticles: surface segregation and atomic-scale structure. J Phys Chem C 115:11355-11363. https://doi.org/10.1021/jp200 642d

8. Mallin MP, Murphy CJ (2002) Solution-phase synthesis of sub-10 $\mathrm{nm} \mathrm{Au-Ag} \mathrm{alloy} \mathrm{nanoparticles.} \mathrm{Nano} \mathrm{Lett} \mathrm{2:1235-1237.} \mathrm{https://}$ doi.org/10.1021/nl025774n

9. Chen $\mathrm{YH}$, Yeh CS (2001) A new approach for the formation of alloy nanoparticles: laser synthesis of gold-silver alloy from gold-silver colloidal mixtures. Chem Commun. https://doi. org/10.1039/b009854j

10. Rodríguez-González B, Burrows A, Watanabe M, Kiely CJ, Marzán LML (2005) Multishell bimetallic AuAg nanoparticles: synthesis, structure and optical properties. J Mater Chem 15:1755-1759. https://doi.org/10.1039/b500556f

11. Tokonami S, Morita N, Takasaki K, Toshima N (2010) Novel synthesis, structure, and oxidation catalysis of $\mathrm{Ag} / \mathrm{Au}$ bimetallic nanoparticles. J Phys Chem C 114:10336-10341. https://doi. org/10.1021/jp9119149

12. Zhang H, Okuni J, Toshima N (2011) One-pot synthesis of Ag-Au bimetallic nanoparticles with Au shell and their high catalytic activity for aerobic glucose oxidation. J Colloid Interface Sci 354:131-138. https://doi.org/10.1016/j.jcis.2010.10.036

13. Sanyal U, Davis DT, Jagirdar BR (2013) Bimetallic core-shell nanocomposites using weak reducing agent and their transformation to alloy nanostructures. Dalton Trans 42:7147-7157. https://doi.org/10.1039/C3DT33086A

14. Wang C, Yin H, Chan R, Peng S, Dai S, Sun S (2009) One-pot synthesis of oleylamine coated AuAg alloy NPs and their catalysis for CO oxidation. Chem Mater 21:433-435. https://doi. org/10.1021/cm802753j
15. Devarajan S, Bera P, Sampath S (2005) Bimetallic nanoparticles: a single step synthesis, stabilization, and characterization of $\mathrm{Au}-$ $\mathrm{Ag}, \mathrm{Au}-\mathrm{Pd}$, and $\mathrm{Au}-\mathrm{Pt}$ in sol-gel derived silicates. J Colloid Interface Sci 290:117-129. https://doi.org/10.1016/j.jcis.2005.04.034

16. Pal A, Shah S, Devi S (2007) Synthesis of Au, Ag and Au-Ag alloy nanoparticles in aqueous polymer solution. Colloids Surf A Physicochem Eng Asp 302:51-57. https://doi.org/10.1016/j. colsurfa.2007.01.054

17. Latif-ur-Rahman R Qureshi, Zia-ur-Rehman A Shah (2012) Synthesis, characterization and applications of bimetallic (Au-Ag, Au-Pt, Au-Ru) alloy nanoparticles. Rev Adv Mater Sci 30:133-149

18. Sun L, Luan W, Shan Y, Tu ST (2012) One-step synthesis of monodisperse $\mathrm{Au}-\mathrm{Ag}$ alloy nanoparticles in a microreaction system. Chem Eng J 189-190:451-455. https://doi.org/10.1016/j. cej.2012.02.043

19. Wang D, LiY (2011) Bimetallic nanocrystals: liquid-phase synthesis and catalytic applications. Adv Mater 23:1044-1060. https:// doi.org/10.1002/adma.201003695

20. Fabrikanos A, Athanassiou S, Lieser KH (1963) Darstellung stabiler hydrosole von gold und silber durch reduktion mit Äthylendiamintetraessigsäure. Zeitschrift Fur Naturforsch Sect B J Chem Sci 18:612-617. https://doi.org/10.1515/znb-1963-0805

21. Wang D, Liu Y, Zhou X, Sun J, You T (2007) EDTA-controlled onepot preparation of novel shaped gold microcrystals and their application in surface-enhanced Raman scattering. Chem Lett 36:924-925. https://doi.org/10.1246/cl.2007.924

22. Bonggotgetsakul YYN, Cattrall RW, Kolev SD (2011) The preparation of a gold nanoparticle monolayer on the surface of a polymer inclusion membrane using EDTA as the reducing agent. J Membr Sci 379:322-329. https://doi.org/10.1016/j.memsc i.2011.06.003

23. Liu L, Wei T, Guan X, Zi X, He H, Dai H (2009) Size and morphology adjustment of PVP-stabilized silver and gold nanocrystals synthesized by hydrodynamic assisted self-assembly. J Phys Chem C 113:8595-8600. https://doi.org/10.1021/jp810668x

24. Sreeprasad TS, Pradeep T (2011) Reversible assembly and disassembly of gold nanorods induced by EDTA and its application in SERS tuning. Langmuir 27:3381-3390. https://doi.org/10.1021/ la104828e

25. Shevchenko GP, Zhuravkov VA, Osipovich NP, Shishko GV (2019) Synthesis of gold hydrosols in the presence of $\mathrm{Na}_{2}$ EDTA. J Belarus State Univ Chem. https://doi.org/10.33581 /2520-257x-2019-1-86-94

26. Zhu J (2005) Theoretical study of the optical absorption properties of Au-Ag bimetallic nanospheres. Phys E Low-Dimens Syst Nanostruct 27:296-301. https://doi.org/10.1016/j.physe .2004.12.006

27. Anderegg G (1979) Critical survey of stability constants of EDTA complexes (IUPAC chemical data series No. 14). Anal Chim Acta 105:461. https://doi.org/10.1016/s0003-2670(01)83794-6

28. Dozol H, Mériguet G, Ancian B, Cabuil V, Xu H, Wang D, AbouHassan A (2013) On the synthesis of Au nanoparticles using EDTA as a reducing agent. J Phys Chem C 117:20958-20966. https://doi.org/10.1021/jp4067789

29. Shevchenko GP, Zhuravkov VA, Tretyak EV, Shautsova VI, Gaiduk PI (2014) Special features of synthesis of silver hydrosols in the presence of the $\mathrm{Na}_{2}$ EDTA. Colloids Surf A Physicochem Eng Asp 446:65-70. https://doi.org/10.1016/j.colsurfa.2014.01.027

Publisher's Note Springer Nature remains neutral with regard to jurisdictional claims in published maps and institutional affiliations. 